\title{
Incorporating SDG 8 for Decent Work Practices: A study of MNC Subsidiaries in India
}

\author{
Fehmina Khalique ${ }^{1}$, Poornima Madan ${ }^{2}$, Geetika Puri ${ }^{3}$ and Daleep Parimoo ${ }^{4}$
}

\begin{abstract}
:
The objective of Sustainable Development Goal (SDG 8) in the 2030 Agenda for Sustainable development is to attain economic prosperity through Decent Work across the member nations of the United Nations. In order to achieve this goal in the next 10 years it is the responsibility of the Governments across the globe to work for its attainment by leveraging through its business houses and corporates at large. The target for decent work for all includes equal opportunities and equal pay for all that leads to economic development. India has already started working on the target by implementing various schemes attached to SDG 8 and to supplement it through organisations across the country that are including these SDG targets into their strategic goals and mission and vision statements up to a large extent.

The current study delves into the role of Multi-National corporations (MNCs) operating out of India in incorporating workforce diversity, equal opportunity and inclusive growth of its employees by providing a decent work environment. The study focuses on 9 MNCs having headquarters in the United States of America and Europe and operating as subsidiaries in Delhi, NCR. The data was collected through secondary sources like websites, HR manuals and Annual reports. The data was qualitatively analysed and presented in the form of small cases for each MNC. These business conglomerates operate through best practices and policies. These practices are disseminated through Human Resource department that acts as a backbone for the MNCs. The study reveals that workforce diversity is prevalent in these MNCs and equal opportunity is also practiced. The implications of the current study are that other private and public enterprises or start-ups can take learning from these MNCs that form a benchmark for implementing workforce diversity in their operations. This will lead to achieving not only business goals but also help in building better economy for the country.
\end{abstract}

Keywords: MNCs, SDG 8, Decent Work, Workforce diversity

JEL Codes: M52, M54, N35

\footnotetext{
${ }^{1}$ Sharda University, India

${ }^{2}$ Amity University, India.poornima_tejpal@yahoo.com

${ }^{3}$ Gitarattan International Business School, India

${ }^{4}$ Sharda University, India
} 


\section{Introduction}

This research paper deals with the eighth United Nations (UN) Sustainable Development Goal (SDG 8) that encompasses to build and promote sustainable and inclusive economic growth leading to full and productive employment along with decent working conditions and practices for everyone. The current paper revolves around these SDGs from the perspective of Multi-National Corporations (MNCs) based out of India in the Information Technology/ Information Technology enabled services(IT/ITeS) sector. It aims to understand the decent work environment followed at MNCs in achieving the SDG 8 by 2030. The paper entails a general overview of United Nations SDGs with special attention to SDG 8 revolving around decent work that includes workforce diversity, equal opportunity, opportunities for the disabled, gender equality, equal pay for all and the like.

The study focuses on the IT/ITeS foreign MNCs located in NCR, mainly Gurgaon and Noida The primary objective of the study is to study decent work environment present in the nine 'Fortune 500 ' subsidiaries. In order to realise the study objective secondary data were collected. The secondary data were collected through company websites, Annual reports and HR manuals of these subsidiaries which are presented in the form of case-let in the study. The paper is presented in the form of case-lets dealing best practices and policies entailing SDG 8 in the form of programmes leading to equal opportunities, workforce diversity etc. These MNCs under study are the leading organisations having headquarters in the United States of America and Europe and their subsidiaries act as independent units in India.

The research paper concludes with giving insights on working environment pertaining to workforce diversity, equal opportunity, inclusive growth which forms important practices in accomplishing organisational goals with special reference to SDG 8. The research also proposes future implications of the study since investment in these practices by organisations will lead to higher economic growth for the nation. These economically sound organisations will help build better economy of the nation thereby uplifting employment and achieving targets and indicators attached with SDG8.

\section{Literature Review- Role of Corporates in SDGs}

93 nations who are the members of UN together agreed to adopt Sustainable Development Goals which are often referred to as "Global Goals" in order to meet sustainable development agenda for 2030 in the "United Nations Sustainable Development Summit" that took place in 2015. The Global Goals enlist largely three dimensions pertaining to sustainability related to economy, society and environment. There were 17 SDGs laid down in the summit and 169 interlinked targets that included eradicating poverty, taking action against climate change, economic growth and decent living that helps in building a sustainable and prosperous world for the future generations.

These SDGs planned in the UN for implementing them in the span of fifteen years demands substantial hard work not only through government initiatives but also from business organisations. Needless to mention, these SDGS are being implemented by Government of Indian where these SDGs act as a blueprint for policy making at the national level and reinforcing laws 
and regulations pertaining to these SDGs. However, government policies can be successfully implemented if they are incorporated and planned at organisational and corporate level for action.

As per the study conducted by Clark et al (2015), it the sustainable development that forms the bedrock for upward growth of financial markets for decades. It is an important aspect for all the stakeholders of the businesses whether in the form of investors' desire for sustainable responsible investing or business management focus on corporate social responsibility. The sustainability practices result in comparatively better organisational performance and lead to lower cost of capital (Armstrong, 2020).

For effective sustainable development for an organisation, it should be aligned with strategic planning. Needless to mention, economic development can be carried out if it meets the demands of all the stakeholders of the organisation that includes shareholders, investors, customers, employees, suppliers and society who are directly or indirectly associated with business activities. Moreover businesses largely depend on human and natural resources apart from physical and financial capital; therefore, the business and economic activities must not irreparably deplete these resources. Leading organisations, societies and government should focus to achieve three major goals, namely, environmental protection, social wellbeing and economic development.

According to GlobeScan Sustainability survey (2017), one out of three organisations in India aligns SDGs with their long-term strategic planning. The top management of leading Indian companies are adopting practices and policies to engage with Global Goals. Nevertheless, this amalgamation of SDGs into the corporate goals demand integration and involvement of all the key departments of the organisations, be it marketing, supply chain management, human resources management, administration, and legal departments. However, among these HR department which involves people management plays a critical role in policy implementation.

It goes without saying that HR department of any leading organisation has a major role to play in building sustainable culture. Sustainability is required by businesses to improve the socioeconomic background, generate job opportunities and increase economic wealth of a nation (Harmon et al., 2010). HR department have the scope to implement the SDG 8 of decent work by taking care of employee wellness, healthy, and safe workplace environment. Jithendran and Baum (2000) asserted that effective human resource management practices leads to sustainability. According to their research development of resources and preservation of environment at local as well as global level comes under the purview of HR development. In the context of sustainable development of organisations Kola (2013) concludes in his research that there is an opportunity to align and familiarise sustainable development practices in learning and development programmes designed for executives. Needless to mention, learning and development practices are a means to inculcate an environment that promotes corporate sustainability and environmentally friendly practices.

According to UNESCO (2017) which published "Education for Sustainable Development Goals: Learning Objectives", attention is drawn at difference between various types of learning like cognitive learning, socio-emotional learning and behavioural learning that aims to achieve all the SDGs. It refers to knowledge, skills and capabilities along with motivation and attitudes required to attain these objectives (Boeren, 2019). The current research delves around the learning as a medium through effective learning and development programmes designed for its human capital 
in order to achieve organisational goals that are aligned with Global Goals. The study will also dwell into organisational culture to understand decent work practices prevalent in these MNCs.

As per a study by Futurescape (2020), 60\% of the top 100 organisations in India implant SDGs into their long-term business strategies; all the companies at the top 10 position also map their organisational goals with Global Goals. As per the survey, IT industry is the leading industry where more than 80 percent of these organisations have mapped SDGs with their business goals. In the current study the IT/ITeS organisations are studied to understand what parameters are adopted by them to achieve Global Goals.

\subsection{India's roadmap for SDG 8}

Notably the major four pillars of Decent Work Agenda; a) 'employment creation' b) 'social protection' c) 'rights at work' and d) 'social dialogue' are fundamental to SDGs for 2030 Agenda; and the significance of decent work in achieving SDG is highlighted by Goal 8 which has been defines earlier. As per the SDG 8, by 2030, the member countries of UN should be able to attain productive and full employment along with appropriate employment and equal pay for all the genders, age-groups and differently abled people (ILO, 2020). The current study largely focuses on SDG target 8.5 that states that "by 2030, achieve full and productive employment and decent work for all women and men, including for young people and persons with disabilities, and equal pay for work of equal value". The study will target the MNCs operating in India which align their long-term strategic goals with SDG8 and will find out how far these organisations are able to achieve these goals.

According to ILO (2020) decent work can be defined as what people desire out of their work life. It includes opportunities pertaining to productive work and employment that fosters handsome pay package, job security, social security for family members, personal and career development, right to raise issues, workers' participation in management and equal opportunity and treatment across gender, age-groups and social strata.

As per a report by NITI Aayog (2020) India has aligned its road map with Global Goals and in order to achieve the "SDG goal 8 of Decent Work and Economic Growth for all". There has been a focus on programmes like 'Make in India', 'Start-up India', 'Skill India', 'Digital India' have the major objective of generating full employment for the diverse population of India with a special focus on youth which forms the largest chunk of Indian population. For effective implementation of these goals, the Government is paying immense attention to trade and commerce practices as a building block and by providing conducive working environment to its businesses. Moreover, in order to attain long-term sustainable growth, India needs to focus on the well-being of its working population which should be not only physically and mentally sound but also trained, skilled, educated and diverse. India being a country of millennials has competitive advantages in setting up large-scale businesses that can be accrued with its young and dynamic workforce. However, a country like India which has the advantage of social demographics with $72 \%$ of its population below the age of 32 cannot grow to its full potential until and unless all the issues related to its working population are fully resolved. 
As per a report by NITI Aayog (2016) on India's road map to SDGs, "productivity of labour and resources in the industrial sector can be increased by a) reducing transaction costs in doing business; b) investment in people; c) resource efficiency - beyond energy efficiency; d) new and efficient technologies". This is view, the onus lies on the shoulders of business houses to implement Government policies in an efficient and effective manner. As mentioned earlier, it is the investment in people that will yield long-term beneficial results for an economy. At the outset, it is motivated workforce that leads to attaining organisational goals. These organisational goals when aligned with SDGs will help attain Nations Global Goals.

\subsection{Research Gap}

Past research on SDGs widely focus on its long-term implications for the business stakeholders and its importance for the future generation (Mio et al., 2020); however, there is paucity of research on the role played by MNCs from developed nations in emerging economies like India in achieving Global Goals. Moreover, past research delves into training and development being an important tool for achieving strategic success for the firms (Gusdorf, 2009), but, the concept of utilising this tool to achieve SDGs in an organisation has not been explored up to a large extent. The current research focuses on the MNCs which focus around decent work practices for their employees but incorporating equal opportunity, workforce diversity, inclusion, women empowerment and etc. Let us now take an incisive look into the SDG 8 and its implementation in Indian corporate sector in the following section.

There has been a wide research on MNCs and their workforce composition in the past (Myloni, 2007; Ferner et al., 2005). However, the research on how workforce composition can be utilised to achieve SDGs has not been explored in the past. This diversified workforce composition will help achieve SDG 8 of decent work for an organisation. The organisations should focus on providing an inclusive workforce across the religions, geographies, disabilities, age, caste etc. in order to have a sustainable growth. Let us find out whether the MNCs in focus employ workforce in alignment with the SDG goals or not.

\section{Data Analysis-Decent Work Practices in IT/ITeS MNC Subsidiaries in India}

Post 1991, the government policy on 'foreign direct investment' (FDI) has been as encouraging as it has been attractive. What is more, the country has a huge trained manpower with highly competitive wage-pattern. With a few limitations, it has shown over the past years considerable macro-economic stability. Besides India has a huge potential market with a humungous population of millennials and growing purchasing power along with being one of the fastest developing countries in the world. These and similar considerations have prompted MNCs to converge on the subcontinent.

Of all the developments propelling global business today, the one that is transforming the international management more than any is the rapid advance in IT/ITeS sector. The IT/ITeS industry has been one of the major driving forces enhancing India's growth on economic front. The industry has significantly transformed India's brand image from that of a bureaucratic land to a nation of innovative practices and rising entrepreneurs providing world-class technology services and business solutions at international level. The industry has greatly helped India to achieve success by moving from agriculturally based economy to a knowledge-based economy. 
Furthermore, India is the top destination for entrepreneurs setting up new businesses and a hub for more than 3000 technical based start-ups which is estimated to increase to 12000 in the near future. It is no surprise that most of the Global 2000 and Fortune 500 companies are establishing their subsidiaries in India having world-wide sourcing of IT/ITeS industry which accounts for a major chunk of the global market in off-shoring IT services (NASSCOM, 2018).

Moreover, India has become one of the most favourite outsourcing destinations in the world especially for IT/ITeS industry which accounts for almost 67 per cent of the US\$ 130 billion market. This industry provides for employment more than 10 million workers. The reason is obvious: India provides cost-competitiveness which is almost 3-4 times less expensive than in the US. In light of the very disruptive emerging technologies, the industry is re-imagining itself to become the software/digital solution partner for the entire world. By 2025, it is expected that the IT market would have grown to almost $\$ 4$ trillion.

According to Budhwar et al. (2006) world class service in software sector in India has been possible due to many pronounced reasons. Firstly, more than two million English-speaking graduates are produced in India each year that are ready to work for salaries that are 80 percent lower than in the Western countries like USA and UK. These tech-savvy young workforces provide for efficient and effective services. Secondly, large savings are also possible for MNCs by outsourcing their work processes to India in the form of BPOs and KPOs not only due to abundant availability of inexpensive human resources but also developed infrastructure that offers improved international bandwidth for internet services, software technology parks, and an existing base of fortune $500 \mathrm{MNCs}$ already operating there.

In the light of the evolving IT/ITeS sector in India it would be insight giving as well as interesting to find out the dynamics of the workforce prevalent in these subsidiaries and their alignment with the Global Goals.

Workforce diversity was first introduced in the 1980s by the HR specialists of the United States as a response to demographic changes in the workplace like increase in the number of female, migrant and differently abled workers. Later organisations realised the role of workforce diversity and a major emphasis was laid on ethnic minority, women, the elderly, disabled and gay and lesbian groups for equal rights and opportunities. Consequently, with the introduction of human rights legislation in the 1990s and 2000s, it helped in giving due weightage and value to individual differences in the workplace (Barak, 2005; Maxwell et al., 2001).

The current research throws light on MNC subsidiaries based out of NCR (Gurgaon and Noida) with their headquarter location in the USA and Europe. The study provides a detailed outline of 9 MNCs, most of them listed in Fortune 500 companies of the world operating in numerous locations across the world. In order to maintain the confidentiality and anonymity, the names of these MNCs and their top executives have been masqueraded. The rising stature of these MNCs can be gauged through the successful implementation of their inventive policies and practices that leads to decent work practices. 


\subsection{Alpha Computers, New York}

Having a global presence Alpha Computers, a Fortune 500 company, have operations in over 170 countries. It was set up on early twentieth century with headquarters in New York and subsequently assumed its massive dimensions both in hardware and software. Currently, Vinnie Ronaldo is the CEO of the company. Ever since she assumed charge, the company has grown manifolds. The company produces and sells hardware and software along with providing consultancy services.

Alpha computers arrived in India in rather a big way soon after the economic liberalization in the year 1992. It is headquartered in India at Bengaluru and has major offices in Chennai, Delhi, Hyderabad, Kolkata and Mumbai with sales and services offices virtually all over the country. Over the years the company has grown not only in business but also as an employer of 150,000 professionals and workers in the country, while more than 400,000 workers across the globe.

At present, Indian operations of Alpha Computers' are headed by Padma Goswami who is highly optimistic about the growth of the company in the country. According to her, the company in years to come aims to generate new business, to attract new clients and to grab a larger share of the software market. Alpha Computers' business currently generates revenues close to US $\$ 4$ billion with a robust growth rate of 3 percent nearly year after year.

Decent Work Practices: Business policies related to staffing, promotion, and compensation of employees etc. are aligned with the Global Goals pertaining to equal opportunity, hence, these activities are conducted regardless of considerations of race, religion, gender, caste or disability. The organisation is committed to workforce diversity in order to enable employees' contribution in the best possible manner. Gender diversity permits the female employees across the globe to target leadership positions. Differently abled employees are given opportunities to attend workshops on career development to enhance their potential and elevating their career. Cultural diversity promotes working across cultural differences across boundaries. In order to foster work and life balance Alpha Computers provides flexible working options to all employees and contribute in longstanding commitment to equal opportunity.

\subsection{Anchor Information Systems, California}

Anchor Information Systems is a major contributor in world class IT and engineering services and solutions. It started its operation in 2002 in California, USA and side by side in Noida, India. Over a period of time Anchor has evolved into a tier-one IT services and solutions like telecommunication, broadcasting, manufacturing, retailing companies. It has a workforce of close to 5000 employees and annual turnover of US $\$ 200$ million. It has a global delivery model that centers primarily in Noida and includes a nexus of people centric and process driven approach.

Decent Work Practices: People centric culture approach is where the company acquires best of the international IT talent, to showcase to their clients, human resources that are trained and outfitted with state-of-the-art domain knowledge across industries. Since the attrition rate at Anchor is as low as 8 percent chances of business discontinuity are minimal. While in process driven approach the agenda for onsite and offshore delivery is to leverage competencies and skill expertise from across the globe to provide technologically advanced as well as cost-effective services that guarantee customer satisfaction. Anchor's best practices include in-house learning through continuous training programmes, ongoing workshops to maintain work-life balance and 
flexible work options. Anchor offers its employees with attractive incentive schemes and benefits in terms of various discounts, vouchers, etc.

Anchor has a globally-integrated delivery system of networks that allows its employees to work through different locations across geographies as the company believes in building a workforce across gender, nationality and religion. It promotes work-life balance and supports it employees through inclusive policies and assistance programme. The company has made efforts to create a conducive work environment with positivity by promoting forums and platforms that generate awareness and sensitize personnel about the equal rights for all irrespective of positions one holds in the organisation; moreover, with its open-door policy the employees have access to senior management team for voicing their concerns and opinions.

\subsection{Bell Computers, Texas}

Bell computers is an American IT/ITeS MNC listed as top 200 companies in Fortune 500 based out of Texas employing 100,000 people worldwide with gross revenue crossing US\$50 billion. Bell computers deal with sale of computer hardware as well as providing software solutions. Earlier it entered the market being a Bell hardware vendor until it entered IT services through various acquisitions and mergers with a goal of expanding its profile from being into computer hardware/software to delivering world class software-based solutions and services to its enterprise customers.

Around 2016, Bell computers completed its $\$ 60$ billion deal to acquire another software company which is the largest technology merger in history. The new company was named Bell Technologies, which now has a turnover of $\$ 74$ billion in revenue and generates employment for 140,000 people worldwide turning it into the world's biggest privately owned technology MNC.

Bell Computers India Private Ltd. started its operations from Bengaluru in late 1990's and since then has become one of the fastest growing MNCs of India and currently belongs to one of the top three companies in India. It holds offices in Gurgaon, Hyderabad and Mohali and is also one of the largest employee bases outside the United States. It delivers IT solutions and services and support to business customers across the world.

Decent Work Practices: Bell operates on an organisational structure that induces participative style of management and empowers its employees which gives them equal opportunity rights. Moreover, its organisational structure does not promote any hierarchical system, thereby, motivating the employees to showcase their potential leading to high performance by organisation. In order to make sure about equal opportunity at work place and consistent HR policies, it has ethical code of conduct which gives importance to ethical standards for all the stakeholders of the organisation. Bell also believes in participative style of management and employee empowerment.

\subsection{GenTech, New York}

GenTech is an MNC having offices in New York City, United States with net revenue of US\$2.50 billion and more than 70,000 employees across 25 nationalities. The company was 2 nd in their IT/ITeS services as well as BPO/KPO and 21st in "Top 25 Best Companies to Work For" in India while CareerBliss ranked it 23rd in "Top 50 Happiest Companies in America". All this recognition is understandable; over the years, GenTech has a reputation of work culture that promotes teamwork 
for employees, customer-centric approach and on-going progress and improvement in business activities.

Decent Work Practices: GenTech is a firm believer in workforce diversity from a gender standpoint, for which it has set a target of 25 percent of women workforce at top level, and has undertaken actions to achieve this through hiring, developing and retaining its women employees. Through its relentless development and retention of talent, the company fosters professional development of women workforce and mentoring program to train middle-level management women to be experienced leaders. The company also assists them with several flexible HR practices including work from home, flexible timing, extended maternity leave, child care, sabbatical etc.

GenTech is an organisation that primarily focuses on talent in the workplace and believes that in the current digital age putting people first is the mantra for sustainable development. At GenTech a culture is created and reinforced that is build through collaborating, innovating through continuous improvement in business processes. The company also seeks to attract, retain and develop talented workforce that showcase dedication, innovation and courage for building a work environment consistent with the ethical code of conduct laid down by the organisation.

\subsection{Globe Systems, California}

Globe Systems is a North American MNC based out of San Jose, California. Globe has traditionally focused its attention on creating multimedia and software products, shifting currently towards internet application-based software development. The company is pioneer and market leader in image-editing with its revenue growing over US \$5 billion and giving employment to more than 15000 people.

Globe Systems started its India operations in the year 1997 with current workforce count exceeding 3500 professionals. Most of the successful products of the MNC are developed and packaged in India itself. According to a survey by Fortune, the company is ranked as "An outstanding place to work" and bagged "One of great places to work" title.

Decent Work Practices: The policy at Globe system regarding sustainability is to sensitize the employees about the environment protection for sustainable development. In order to achieve its goals regarding sustainable development, the company takes all the possible measures to reduce all Scope 3 emissions by reaching to their suppliers about the issue; employees are encourages for using public transportation, zero-carbon commuting for work, and reducing employee travel through policies like "Skip a Trip: use Connect (or digital meetings) instead". Moreover, the company believes in educating and engaging workforce on sustainability development while at home and work through their learning and development sessions that communicate about the rising environmental concerns.

\subsection{Neptune Technologies, Massachusetts}

Neptune Technologies was set up in 1990 in Massachusetts, USA and deals in business, marketing, and technology services. During '90s', Neptune Technologies was the pioneer in dealing with its products based on internet-based technology thereby increasing number of clients and projects multifold. Neptune Technologies has sought to expand its business as a leader of emerging markets through several mergers and acquisitions. 
Neptune Technologies was set up in India in 1998 with operations in Gurgaon and Bengaluru and has organically grown to more than 8500 people. The company believes in delivering high quality standards by providing training specific to financial services and technology. It is ranked as one of the "leading employers" and rated among the top ten "companies to work for" in India according to Business Today and Mercer Consulting respectively.

Decent Work Practices: At Neptune Technologies India, an average employee age is just 27 and about 27 percent of the company's workforce comprising women. The infrastructural layout at offices of Neptune centres has is open and it is difficult to find out hierarchical differences that supports core values of the company. Whiteboards are frequently used for meetings and planning sessions. The company has received global recognition for its innovative and collaborative workplace including the prestigious "IIDA Gold Award" for corporate office design.

\subsection{Quantum Electronics, France}

Quantum Electronics is a French MNC that deals in manufacturing of semiconductor and headquartered in Switzerland and is placed as Europe's largest semiconductor chip manufacturer. The company employs more than 50,000 professionals with revenue above US $\$ 8$ billion and operating income US $\$ 465$ million. The India office was set up in 1987 as a liaison office with a few employees; since then it has evolved into 1500 plus employees' company with being the first semiconductor company. Its Indian operations are one of the largest outside Europe due to cost competitiveness and availability of engineering professionals which lead to its multifold growth. The company has brought laurels due to its engineering marvels in development and industrialization of a wide range of products for automotive, consumer, computer, telephony, and industrial applications. It is one of the top suppliers of semiconductors in India and has been recently ranked among the 25 "best employers in India" and also received the prestigious IMPRESA award for bringing European best organisational practices to the country.

Decent Work Practices: Organisational policies at Quantum are based on the assumption that the development of employees' skills and profiles is matched with its business needs, in order to reach the maximum organization performance thereby increasing employability. HR practices like lifelong learning through professional development define the career path of its employees. The working culture here encourages innovative thinking, risk taking, result oriented, problem solving and employee's empowerment to meet the ever-growing customer demands and expectations.

The company boasts about its top management in which 40 percent come from other geographies. The company has policies and programmes in alignment with the SDGs for hiring workforce not only on the basis of their technical abilities but also from different walks of life including 39 percent of women workforce, differently abled, ethnic minorities, immigrants and the like. Moreover, the proportion of women at top level management is steadily increasing in Quantum with the promotion rate of women employees being almost same as their men counterparts. The company also ensures equal opportunities for employees with disabilities as a part of business strategy of workforce diversity. The organisation builds its leaders through its unique culture and leadership objectives which are transferred in certain ways, for example to articulate and communicate a convincing vision, alignment of activities to organisational strategy and deliver results, encourage a climate of innovation and entrepreneurship, and attention to executive growth and employee engagement. 


\subsection{SpectraNet, Connecticut}

SpectraNet Corporation is based out of Connecticut, USA and deals in business services and document technology products. The company is consistently placed in the list of Fortune 500 companies and has crossed over US $\$ 11$ billion in revenue. In early twenty first century, it was announced by SpectraNet that the company would be headed by the first African American woman as its CEO. Later, the company saw major acquisitions for various strategic reasons.

SpectraNet India, established its base in India in early 1980s with a joint venture with an Indian conglomerate. Later, SpectraNet obtained a majority stake in the beginning of year 2000 of the company and aims to buy out the remaining shareholders as well. SpectraNet operates in India as a BPO (business process outsourcing); being a leader in the industry the company helps its clients improve their workflow by leveraging its capability in managing transaction intensive processes. Karan Malhotra serves as the Indian CEO.

Decent Work Practices: The ongoing mission of SpectraNet is to ensure a working culture and environment equal opportunity is nurtured along with dignity and respect for its members; and where an employee's individual existence is aligned with the company's high-performing teams. The balanced workforce strategy at SpectraNet drives equitable employee representation in all areas; its work life balance policies help employees in their personal lives. The workforce diversity includes commitment at top level executives and communications through which the company educate employees on diversity programmes and policies. Presently, SpectraNet is considered as one of the most advanced companies to work with which has been felicitated with awards for building and maintaining an inclusive corporate culture. The company fulfills the social goals in alignment with the Global Goals for Sustainable Development through balanced workforce diversity and workplace safety for its employees.

\subsection{Weblogic, California}

Weblogic was incorporated in the year 2000 at its headquarters in San Jose, California USA and provides to its customers one of the best software research and development services company. It has its development facility in Noida. The company provides services related to product development and engineering, big data and business analytics, cloud computing, Internet of Things, mobile services and software security. The company has a client base with both start-ups and mature product and services companies in the field of automotive, finance, media and communications, medical technology, and retail industries. It has more than 11000 employees worldwide with revenue crossing US\$ 550 million. According to a survey by glassdoor.com Weblogic has been listed among the top 25 companies for work-life balance and has been recognised as a pioneer in social recruiting and hiring methods by LinkedIn.

Decent Work Practices: Weblogic initiative for corporate social responsibility is based on the fact that promoting education and skills development for all sections of the society is pivotal for developing economies like India to nurture a progressive ecosystem. The organisation is committed towards inclusion and workforce diversity and has dedicated internal resources who volunteer to lead the CSR activities in their Indian subsidiary. Through the Weblogic foundation 
created for CSR activities, the employees can participate in several programs designed to strengthen the communities where they work and live.

The aforementioned write-ups provide a bird's eye-view of some notable subsidiaries of MNCs whose network, in most cases, is global. These MNCs are not only mammoth companies, but also have, apparently, ushered in a mini revolution in organisational practices in order to align the strategic business goals with the Global Goals. These MNCs foster an environment conducive for decent work practices like equal opportunities, fair pay, employee participation, women empowerment etc. Furthermore, these MNCs build on a competent and talented workforce that us inclusive and diverse from all the aspects. The MNCs establish structure which is flexible, follows the latest norms and is backed by resourceful workforce.

\section{Discussion and Conclusion}

According to a report by NITI Aayog's (2016) on India's road map to SDGs, certain recommendations were made in order to achieve SDG 8 in an efficient and effective manner at macro level. Firstly, employment opportunities should be the focus for long-term sustainable growth objective by creating jobs for the youth; awareness drive regarding Government schemes like Make in India, Mudra scheme, etc., should be made across the nation; and focusing attention on labour intensive sectors. Secondly, substantial employment opportunities can be generated by paying attention to strategies centered on local market development; livelihood business incubators should be established in both urban and rural areas. Thirdly, the workforce should be self-driven and motivated if provided with social security for the family members like health insurance, pension, etc.; there should be technical education and vocational training for skill-development and enhancement; Fourthly, to ensure decent work, a series of labour reforms have to be enabled across states; user service reforms can be enabled through single online window; in line, inspection reforms by ensuring computer generated online information. Fifthly, digitization of Government and private employment portals and employment exchanges, IT enabled service delivery through employment exchanges and skill upgradation and knowledge sharing and transfer for employment opportunities. Lastly, linking private placement and training agencies with the employment portal at the state level thereby integration with the national portals. These recommendations are implemented and carried out at national level in order to achieve the SDG 8 for the nation. However, these can be achieved effectively only through the intervention of Corporate sector.

Organisations and businesses take action to incorporate and implement sustainable management solutions through its strategic policies and programmes assuming that the workforce is aware of corporate sustainability policies and procedures. However, this may not be true and these employees may actually be unaware of issues pertaining sustainable development which are beyond their working capacity and responsibilities (Helen and Talwar, 2010). The role of leaders comes handy in such situation where the organisational policies and practices regarding the SDG targets are disseminated amongst the workforce. According De Silva et al. (2020) it is the role of leaders of a business enterprise to lead by example and set up ethical practices in order to implement effective corporate social responsibility and corporate citizenship.

According to a report by FICCI(2020) on Sustainable Development Goals Linkages with corporate actions in India, it is important for private and public business houses to act as change agents in order to promote and incorporate SDGS, and gain competitive advantage by leveraging on the 
opportunities through aligning SDGs with corporate strategies. Needless to mention, the Indian organisations have been focusing for a very long time on addressing sustainability and climate change issues. These SDGs devised at the UN summit, however, helps to bring out a sea change in the mindset and perception of various stakeholders who seek to address sustainability challenges till the year 2030. The organisations have long realised that devoting time, effort and money through its resources in SDG strategies will help them go a long way to stay in business, have a cutting edge over competitors, helps in risk mitigation, and reduces supply chain cost. Furthermore, it leads to better and improvised product development and brand value along with opening new market opportunities for Indian businesses across geographies.

With respect to workforce diversity the MNCs are open to women inclusion at all levels. In this they give due weightage to achievement and performance rather than the conventional gender considerations. It is culled out from the data gathered from 9 MNCs in the current study that top MNCs in India in the IT/ITeS sector practice people-centric approach of equal opportunity, work force diversity, conducive working environment, better employment opportunities through skill development and give due consideration to its human resources. These leading MNCs have grown in stature and size over the past several years and have gained cutting edge over its competitors. Success of these corporates will lead to generation of employment and development of resources in the long-term leading to better economic growth.

\subsection{Limitations and Scope of future Studies}

The current study deals with only IT/ITeS MNCs; however, an extensive study based across industries is needed in order to understand the realisation of SDG goal 8 involving decent work practices. The future studies can involve primary and secondary data of not only MNCs but also indigenous organisations that give emphasis on decent work practices. This will not only help to understand the workforce composition and implementation of SDG8 sub-goals like equal opportunity, women empowerment, decent pay etc. but also help the organisations to fulfill their strategic objectives thereby achieving national economic development goals. The study takes into account only learning and development as a strategic tool for realising SDG 8, however, there can be other tools and ways that can help increase awareness about the SDGs and hence there is a scope for future studies on the role of HR in achieving SDGs.

\subsection{Implications of the study}

There are several implications of the current study on the Indian economy a whole and private sector organisations in particular. This study lays a foundation for the HR practitioners as well as the top level management in implementation of Global Goals. The study would help the business managers to gauge into the workforce composition and engage in workforce diversity that would help them gain competitive advantage over others. Such organisational policies and practices pertaining to SDGs derived from Fortune 500 companies becomes a benchmark for other start-ups or new companies. The involvement of emerging economy MNC host-country like India and its stakeholders with the parent country stakeholders will not only create development opportunities for the emerging economies but also will be beneficial for sustainable development of the world (Hendriks, 2017). 


\section{References}

Armstrong, Anona. (2020). Ethics and ESG. Australasian Accounting, Business and Finance Journal, 14(3), 6-17. doi:10.14453/aabfj. v14i3.2

Barak, M. E. M. (2016). Managing diversity: Toward a globally inclusive workplace. Sage Publications.

Boeren, E. (2019). Understanding Sustainable Development Goal (SDG) 4 on "quality education" from micro, meso and macro perspectives. International Review Education, 65, 277-294. doi: https://doi.org/10.1007/s11159-019-09772-7

Budhwar, P. S., Luthar, H. K., \& Bhatnagar, J. (2006). The dynamics of HRM systems in Indian BPO firms. Journal of Labor Research, 27(3), 339-360. doi: https://doi.org/10.1007/s12122-006-1027-7.

Clarke, G.L., Feiner, A., \& Viehs, M. (2015). From the Stockholder to the Stakeholder: How Sustainability can drive financial out performance. Oxford University Press. doi:https://doi.org/10.2139/ssrn.2508281

De Silva, Lokuwaduge., Chitra S., Smark, Ciorstan and Mir, Monir. (2020). Sustainable Development Goals and Businesses as Active Change Agents. Australasian Accounting, Business and Finance Journal, 14(3), 1-5. doi:10.14453/aabfj. v14i3.1

Ferner, A., Almond, P., \& Colling, T. (2005). Institutional theory and the cross-national transfer of employment policy: The case of 'workforce diversity' in US multinationals. Journal of International Business Studies, 364-321. doi:http://dx.doi.org/10.1080/09585192.2016.1246461

FICCI. (2020). Sustainable Development Goals Linkages with corporate actions in India. Retrieved from http://ficci.in/spdocument/22950/Sustainable-Development-Goals-ficci.pdf (Accessed Oct 2020)

Futurescape. (2020). India's Top Companies and the SDGs. Retrieved from https://www.futurescape.in/responsible-business-rankings/indias-top-companies-and-the$\underline{\text { sdgs/ (Accessed Oct 2020) }}$

GlobeScan Sustainability survey. (2017). Sustainability leaders: Celebrating 20 years of leadership. Retrieved from https://globescan.com/wp-content/uploads/2017/07/GSS-Leaders-2017-Survey-

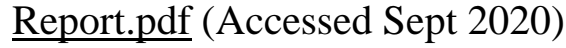

Gusdorf, M. L. (2009). Training Design, Development and Implementation. Society for Human Resource Management (SHRM), 1-34. 
Harmon, J., Fairfield, K. D., \& Wirtenberg, J. (2010). Missing an opportunity: HR leadership and sustainability. People and Strategy, 33(1), 16.

Haugh, H. M., \& Talwar, A. (2010). Sustainability in Management Education. Academy of Management Learning \& Education, 9(3), 384-396. doi:10.5465/amle.9.3.zqr384

Hendriks, G. (2017). The sustainable development effects of investment by emerging market multinationals: Shaping beneficial outcomes for home and host country. Transnational Corporations, 24(3), 73-88. doi: 10.18356/0fe3debf-en

ILO. (2020). Decent Work and Sustainable Development Goals. Retrieved from http://www.ilo.org/global/topics/decent-work/lang--en/index.htm

(Accessed Sept 2020)

Jithendran, K. J., \& Baum, T. (2000). Human resources development and sustainability-The case of Indian tourism. International Journal of Tourism Research, 2(6), 403-421. doi:https://doi.org/10.1002/1522-1970(200011/12)2:6<403::AID-JTR239>3.0.CO;2-3

Kola-Olusanya, A. (2013). Embedding Environmental Sustainability Competencies in Human Capital Training and Development. Mediterranean Journal of Social Sciences, 4(4), 65. doi:10.5901/mjss.2013.v4n4p65

Maxwell, G. A., Blair, S., \& McDougall, M. (2001). Edging towards managing diversity in practice. Employee Relations. 23(5), 468-82.

Mio, C., Panfilo, S., \& Blundo, B. (2020). Sustainable development goals and the strategic role of business: A systematic literature review. Business Strategy and the Environment, 29(8), 3220-3245. doi: https://doi.org/10.1002/bse.2568

Myloni, B., Harzing, A. W., \& Mirza, H. (2007). The effect of corporate-level organizational factors on the transfer of human resource management practices: European and US MNCs and their Greek subsidiaries. The International Journal of Human Resource Management, 18(12), 2057-2074. doi: https://doi.org/10.1080/09585190701695226

NASSCOM. (2018). Nasscom report on Outlook for Indian Software Product Businesses. Retrieved from

http://www.investingintamilnadu.com/india/doc/IT/NASSCOM_Report_Indian_Software.pdf

(Accessed Oct 2020)

NITI Aayog. (2016). India's roadmap for SDG 8 - A Brief Introduction. Retrieved from https://niti.gov.in/writereaddata/files/Report_SDG-8.pdf

(Accessed Sept 2020)

NITI Aayog (2020). SDG India 2019-20. Retrieved from HTTPS://NITI.GOV.IN/SITES/DEFAULT/FILES/SDG-INDIA-INDEX-2.0_27-DEC.PDF (Accessed Nov 2020) 
UNESCO. (2019). Education for Sustainable Development Goals: Learning objectives. Paris: Retrieved from https://www.unesco.de/sites/default/files/201808/unesco_education_for_sustainabl e_development goals.pdf (Accessed Mar 2020) 